\title{
Identity, Social Mobility, and Trauma: Post-Conflict Educational Realities for Survivors of the Rohingya Genocide
}

\author{
Naved Bakali ${ }^{1, *(1)}$ and Shujaat Wasty ${ }^{2}$ \\ 1 School of Education, American University in Dubai, Dubai, Sheikh Zayed Road, Dubai 28282, UAE \\ 2 OBAT Canada, Nepean, ON K2G 5Y7, Canada; shujaat.wasty@obatcanada.org \\ * Correspondence: nbakali@aud.edu
}

Received: 18 February 2020; Accepted: 8 May 2020; Published: 12 May 2020

\begin{abstract}
The Rohingya refugee crisis is a humanitarian disaster with over 740,000 Rohingya leaving their homes in Rakhine State, Myanmar, since August 2017. In the process of this mass exodus, thousands have been brutally murdered and terrorized through a campaign of physical attacks by the Myanmar state including murder, beatings and mutilations; mass gang rape and sexual slavery of women and girls; and the burning of entire villages. The victims have been men, women, and children who were targeted because they belonged to a Muslim minority ethnic group. The crisis has been recognized as genocide by officials from several countries including Canada, France, Gambia, Malaysia, Pakistan, Philippines, and Turkey. Furthermore, a recent ruling by the International Court of Justice (ICJ) ordered Myanmar to take all necessary measures to prevent the genocide of the Rohingya. The genocide of the Rohingya has resulted in a massive number of refugees fleeing to Bangladesh, with 1.1 million of an estimated 2.4 million Rohingya across the world currently encamped there. This crisis has led to questions about how the basic needs of these refugees are being met and if there is any possibility for a life beyond the refugee camps through educational programming. This study explores the educational realities of Rohingya refugees through a process of open-ended and semi-structured interviews of aid workers and educators working in the Kutupalong refugee camp in Bangladesh. Through examining the educational programming in these camps, this article aims to better understand the educational opportunities for social mobility, identity preservation, and the availability of religious instruction to the Rohingya. The findings of this study suggest that religious instruction centers may serve to improve gender- based educational gaps for adolescent Rohingya women.
\end{abstract}

Keywords: Rohingya; post-conflict education; refugees; Islamic education; identity; social mobility; gender

\section{Introduction}

The Rohingya refugee crisis is one of the greatest humanitarian disasters of its generation. More than 740,000 Rohingya have been expelled from their homes in Rakhine State, Myanmar, since August 2017 (The United Nations High Commissioner for Refugees 2019). This mass exodus has been incited by an organized campaign against the Rohingya by the Myanmar state. Rohingya men, women, and children were targeted because they belonged to a largely Muslim minority ethnic group, with thousands brutally murdered and traumatized through physical attacks, sexual violence, and the burning of villages (McPherson 2017). In September 2018, Canada recognized the crimes committed against the Rohingya at the hands of the Myanmar military as constituting genocide, and urged the United Nations (UN) Security Council to act (Harris 2018). A UN investigative report released in 
August 2018 stated that top military commanders in Myanmar should be investigated and prosecuted for the "gravest" crimes against civilians under international law, including genocide (United Nations News 2018). In November 2019, Gambia filed a lawsuit with the International Court of Justice (ICJ) in The Hague, accusing Myanmar of genocide (Simmons 2019). Consequently, on 23 January 2020, a panel of 17 judges at the ICJ unanimously ordered Myanmar to take all necessary measures to prevent the genocide of the existing Rohingya in Myanmar, including the prevention of killing, causing serious bodily or mental harm to the Rohingya, as well as preserving evidence of possible genocide that has already occurred (BBC 2020). The genocide of the Rohingya has resulted in a massive number of refugees fleeing to Bangladesh. With 1.1 million of an estimated 2.4 million Rohingya across the world currently encamped as refugees in Bangladesh (Habib et al. 2018) and Kutupalong now recognized as the largest refugee camp in the world (OCHA 2020), questions arise as to how the basic needs of the refugees are being met, and if there is any possibility for social mobility beyond the camps through the educational programming that is available.

This study examined the challenges faced by educators and aid workers in providing educational programming and services to the Rohingya refugees in the Kutupalong refugee camp. According to Dryden-Peterson (2016), 86\% of refugees globally end up in temporary settlements in neighboring countries where access to educational resources, long-term permanency, and access to rights is tenuous. This study builds on this literature as it provides insights into this recent massive influx of Rohingya refugees. The three primary objectives of this study were: (1) to better understand the educational realities of Rohingya youth living in Kutupalong; (2) to contribute towards academic research and literature that may serve to improve educational programming for Rohingya youth in the camp; and (3) to provide a space for aid workers and educators who are working in the Rohingya refugee camps to express their concerns, challenges, and expertise on educational initiatives taking place in the camps. The questions guiding this study were: (1) What are the current educational outlets available to Rohingya youth living in Kutupalong?; (2) To what extent is the current educational programming addressing the academic and psychological needs of these survivors of trauma?; and (3) What importance is attached to religious (Islamic) education in the preservation of Rohingya culture and identity?

This study is relevant, as the recent mass migration of Rohingya from Myanmar to Bangladesh represented the fastest growing refugee crisis throughout 2017-2018 (The United Nations 2018). As such, there is very little research and information relating to educational opportunities available to Rohingya youth in the aftermath of this crisis. To better contextualize and provide a holistic understanding of this study, the paper will first examine the historical roots of the Burmese-Rohingya conflict. The unfavourable conditions imposed on the Rohingya discussed in this section of the paper have historically created conditions that have severely limited educational opportunities for the Rohingya (Topol 2019). Thereafter, the paper will describe the methodological framework and approaches employed in this study. This will be followed by an analysis and discussion of the findings of the study, based on the participating educators' and aid workers' interviews, which formed the basis of the data collection. The paper now turns to examine the historical context of the Burmese-Rohingya conflict.

\section{The Historical Context of the Burmese Conflict with the Rohingya}

History of the Rohingya in Myanmar. The Rohingya are a distinct, largely Muslim ethnic group, native to the area of Arakan, which is current day Rakhine State in Myanmar. The Rohingya are one of the many ethnically and linguistically diverse groups residing in Myanmar, who are distinct from the Burmese majority. It is unknown exactly when the Rohingya migrated to Arakan. Some historians believe that the Rohingya are descendants of Indo-Aryan ethnic groups that migrated to the region over three millennia ago (Ibrahim 2018). Others have argued that their presence is a combination of trade migration patterns and the interchange of various ruling dynasties over the region from the 8th to 18th centuries (Bari 2018). What can be said definitively about the Rohingya is that census information obtained during the British colonial occupation of Arakan indicated the presence of an indigenous 
Muslim group called 'Rooinga' that were native to that land prior to the 1820s (Ibrahim 2018). As such, there is strong evidence suggesting that the Rohingya have been indigenous to the Arakan region for centuries. Some may question why the Rohingya differ linguistically and ethnically from the majority of inhabitants of Arakan and Myanmar. One key point to understand is that Arakan, which was at the western edge of Myanmar, bordering Bangladesh, was not historically a part of what constituted the dominion of ethnically Burmese communities. At various points in history, the geographic area of Arakan had fallen into the hands of different rulers from Burma proper, as well as ruling powers such as the Mughals, and ruling dynasties from Bengal (Ware and Laoutides 2018). At some time during the period of $1000 \mathrm{CE}$, there was a mass migration to Arakan of a Burmese ethnic group called the Rakhine. Arakan was composed of various ethnic and religious groups; however, with this mass migration, the Rakhine, over time, came to dominate the region, which eventually became known as Rakhine State. It was through the creation of the nation state in the colonial and post-colonial era that the area currently referred to as Rakhine State formally became a part of Burma proper, now referred to as Myanmar.

This back story of the Rohingya is vital, as the rhetoric used by the military and Buddhist extremist at the forefront of the Rohingya exodus and genocide have consistently reinforced the narrative that the Rohingya are foreigners that were brought in by the British (Wade 2017). Though the British did bring in labor migrants from India during colonial rule to work in various agricultural sectors, they were mostly Hindu (Bari 2018). There is ample evidence suggesting that the Rohingya's existence in Myanmar predates the colonial occupation by centuries, as they were considered one of the many indigenous groups living in the region prior to the arrival of the Hindu labor migrants from India. However, the distinction between the Rohingya and these labor migrants began to fade during military rule in Burma in the 1960s, which was a key turning point leading to heightened tensions towards the Rohingya.

Origins of the conflict. Prior to the colonial period, the Rohingya were one of many indigenous minorities in the region of Arakan. There were instances of strife and discord between these various religious and ethnic groups, however, they lived in relative calm and peace. This changed during the period of British colonial rule of Burma from 1824-1948, which saw the colonizers giving preference to Muslim minorities over the Buddhist majority with regards to social mobility and administration of the colony. This became a starting point of tensions between these religious and ethnic communities.

The tensions were further exacerbated during the period of World War Two when Myanmar was invaded by the Japanese. The Burmese Buddhist majority aligned with the Japanese, while the Rohingya stayed loyal to the British. The British had made promises to the Rohingya with regards to land and autonomy because of their loyalty during this conflict. However, after the war ended, these promises were not honored. In the aftermath of World War Two, tensions between the Burmese majority and the Rohingya worsened due to what the Burmese viewed as conflicting loyalties from the Rohingya. These tensions became intensified when the Rohingya petitioned for parts of Rakhine State to be annexed to East Pakistan during the 1947 Partition of India into India and Pakistan (Wade 2017). When this did not occur, it became clear to the Burmese majority that Rohingya allegiance was tenuous in the Buddhist majority nation.

In the 1947 Burmese Constitution, the Rohingya, along with other minority ethnic groups in Rakhine, were not granted citizenship, but were granted National Registration Certificates, which gave them full legal and voting rights. The Rohingya were informed that they did not need to apply for citizenship certificates because they were recognized as one of the indigenous races of the Union of Burma (Ibrahim 2018). From this it can be inferred that despite existing tensions between various ethnic groups in Burma, the Rohingya were treated like any other minority group, with the eventual possibility of a naturalization process. Unfortunately, this would never come to pass, as military rule drastically changed the political landscape of Burma.

In 1962, Burma came under the military rule of Ne Win in a coup d'état. The Rohingya were steadily losing their rights under the military regime and experienced a major shift in 1974 through the 
Emergency Immigration Act (Ware and Laoutides 2018). This law instituted ethnicity-based identity cards, which identified Burmese nationals. The Rohingya were issued Foreign Registration Cards, designating them as non-nationals. Furthermore, the 1974 constitution, Article 145, stated that "All persons born of parents both of whom are nationals of the Socialist Republic of the Union of Burma are citizens of the Union" (Ibrahim 2018, p. 50). Article 145, along with the Emergency Immigration Act, de facto made the Rohingya stateless, as they were considered foreigners to lands that they had been native to for generations. These severe citizenship restrictions came into effect at a time when the military needed to gain political expediency in the face of economic crisis. They believed that this could be achieved by uniting people through nativist laws and propaganda that targeted minority groups and reinforced the notion of Buddhist identity as a basis for citizenship (Wade 2017). The increasingly stringent laws targeting Rohingya between the 1970s to the 1990s led to mass violence and abuse towards this minority group at the hands of the Burmese Buddhist majority. The state's open targeting of the Rohingya eventually led to 200,000 Rohingya fleeing to Bangladesh in 1978, as well as another wave of 250,000 between 1991-1992 (Ibrahim 2018). In both instances, the Bangladeshi government sent most of the fleeing Rohingya back to Myanmar, who returned to lands that had been confiscated and re-appropriated by the state, forcing many Rohingya to become laborers of lands they once owned (Ware and Laoutides 2018). Ultimately, the targeting of Rohingya was a by-product of economic crises spurned by a disastrous period of military rule. The regime felt it necessary to find internal enemies to detract from the economic crisis that embroiled the nation. The Rohingya were considered an easy and safe target, given the above history, as they differed ethnically, religiously, and linguistically from the Burmese Buddhist majority. Furthermore, as compared to other minorities in the Rakhine region, they were less militarized than other groups (Ibrahim 2018).

The current crisis: There were a number of attempts to democratize Burma during military rule; however, with little success. Things began to slowly change in the aftermath of a natural disaster in 2008 called Cyclone Nargis. Cyclone Nargis had devastating impacts on Myanmar, destroying 65 percent of the country's rice fields and 95 percent of buildings in the delta region. The ferocity of the cyclone was believed to have left an estimated 138,000 dead (Seekins 2008). Under military rule, there was gross mismanagement of the disaster response by the state, which led to restlessness in the nation. To ease some of these tensions, the military was forced to allow new elections in 2010. Through a continual process of political parties boycotting elections and growing public discontent, a democratic government was finally able to come to power in 2015. The National League for Democracy's (NLD) victory, led by Nobel Peace Prize Laureate Aung San Suu Kyi, was hailed by the world as a sign of democratic progress and the potential for a brighter future in Myanmar. A key factor enabling Aung San Suu Kyi to win the election was her ability to gain support from various Buddhist groups. By forging these alliances, the NLD was able to gain popular support. However, the democratically elected government in Myanmar was a façade, as the military had placed checks and balances to ensure its economic dominance and influence within the government (Ware and Laoutides 2018). The military allowed for Myanmar to transition into a democracy by retaining $25 \%$ of its parliamentary seats. These seats were allocated to the Union Solidarity and Development Party (USDP), a political party that served as a front for the military to maintain significant control over the affairs of the nation (Bari 2018). As the military held key positions in the parliament, Aung San Suu Kyi needed to straddle a fine line between acquiescing to the demands of the military, while pandering to the Buddhist populist elites to maintain her base of popular support. In essence, her 'democratically' elected government was steeped in complex power dynamics, which required the NLD to submissively turn a blind eye to the brutal military and Buddhist extremist oppression and violence targeted towards the Rohingya. Consequently, after the 2015 election, oppression and abuse of the Rohingya continued unabated.

The violence and repression in post-democratic Myanmar led to new waves of Rohingya refugees fleeing to neighboring Bangladesh, as well as Malaysia. The exodus of the Rohingya intensified on 25 August 2017, when the self-proclaimed Arakan Rohingya Salvation Army (ARSA), a militant Rohingya group, attacked police outposts killing a dozen officers in retaliation for the longstanding 
violence and repression of the Rohingya. These killings sparked an enormous and disproportionate response by Myanmar's military along with Buddhist extremist mobs. Their response was a scorched earth policy, razing Rohingya villages, mass sexual violence, and the brutal massacre of civilians including men, women, and children (Médecins Sans Frontières 2018). According to a survey by Médecins Sans Frontières (MSF) approximately 9400 Rohingya were killed in Rakhine State between 25 August-24 September 2017, with at least 730 of the victims being children (Médecins Sans Frontières 2018). Researchers have estimated that in the weeks following 25 August 2017, over 24,000 Rohingya were killed by Myanmar's state forces and Buddhist mobs; over 36,000 Rohingya were thrown into fires; over 116,000 Rohingya were beaten; over 18,000 Rohingya women and girls were victims of sexual violence including mass gang rape; and around 128,000 Rohingya homes burned down or vandalized (Habib et al. 2018). The outburst of violence on August 2017 marked the tipping point, which turned years of systemic violence and discrimination against the Rohingya into an act of genocide.

Having discussed the conditions that created the Rohingya refugee crisis, the paper now turns to describe the theoretical and methodological frameworks and processes employed in this study to understand the educational realities of Rohingya refugees in the aftermath of the genocide.

\section{Theoretical and Methodological Frameworks}

This study draws from a critical theory theoretical framework. Critical theory is a foundational body of theory which has influenced a number of methodological and theoretical approaches, such as critical ethnography, critical discourse analysis, critical pedagogy, and critical race theory. It is a theoretical framework which has been used to examine social action, politics, and class relations, as well as other spheres of human activity. Critical theory grounds its analysis on examining the impact of ideologies, such as racism, in lived human experience. This perspective assumes that ideology impacts and shapes the relationship between individuals and groups interacting with one another (Budd 2008). As such, this theoretical lens is appropriate for understanding the lived experiences of oppressed groups who have suffered from trauma, struggled with identity, and have had limited access to social mobility (Budd 2008).

This study employed a critical ethnographic approach to conduct and interpret participant interviews. Critical ethnography is a research methodology used particularly to examine peoples' experiences with social, racial, cultural, and economic oppression and subordination (Cook 2008). It is a methodological approach, which attempts to give voice and agency to marginalized classes, to challenge oppression and subordination. Critical ethnography has been used to examine issues relating to inequity in educational settings (Carspecken and Carspecken 1996). Furthermore, it can be understood as a "research methodology through which social, cultural, political, and economic issues can be interpreted and represented to illustrate the processes of oppression and engage people in addressing them" (Cook 2008, p. 148). Therefore, this methodological approach can be particularly useful when examining oppressed or racialized groups. Critical ethnography involves interviewing subjects and creating a record of observation, collecting field notes, observing participants in social sites, as well as analyzing the social structures with which participants interact with and which impact or influence the social surroundings of participants (Carspecken and Carspecken 1996).

The use of critical ethnography has been taken up in the fields of sociology and cultural studies; however, it has increasingly been used in educational research (Carspecken and Carspecken 1996). Certain assumptions undergird critical ethnography when applied in the field of education. These include the beliefs that "inequality exists in society, mainstream practices often reproduce inequalities, oppression occurs in many forms and is most forceful when it involves hegemonic learning, and critical research should engage in social criticism to support efforts for change" (Cook 2008, p. 148). Therefore, this methodology places emphasis on the lived experiences and agency of participants because it is through their insights that criticism and social change is possible. As this approach recognizes the authority of the participant in describing their lived realities, critical ethnographers must 
engage in a reciprocal process in which the researcher and participants work together in constructing their knowledge of an issue. This process is detailed in the following methodological procedures.

This research project was a two-phase study: (1) recruitment and interviewing of teacher and aid worker participants in Kutupalong; and (2) analysis of interview transcripts of participants. Ethical approval for the research was obtained from the American University in Dubai, United Arab Emirates. Logistical support was provided by OBAT Helpers (USA) and OBAT Canada. Phase one of this study employed critical ethnographic methods as a primary source of data collection. Data collection was composed of audiotaped interviews and field notes taken during the interviews in Kutupalong. For the purposes of feasibility and limited access to the refugee camps because of strict curfew regulations, this study recruited a total of eight participants to engage in in-depth interviews and discussions. Participants were solicited through purposeful sampling. In total, four teachers and four aid workers were interviewed. Two of the teachers were local Bangladeshi hired teachers and the other two were Rohingya educators from the camps. Two of the aid workers were Americans, one of the aid workers was a local Bengali, and the other was a Rohingya refugee, all of whom were employed by NGOs providing aid and services out of the camps. For purposes of anonymity, we assigned pseudonyms to all participants. The two Bengali and two Rohingya teachers' names, respectively, were: Sakina, Salma, Ali, and Hussain. All four teachers completed the equivalency of high school education in either Myanmar or Bangladesh, as well as received educational training through NGOs providing relief efforts in the camps. The names of the two American aid workers were Sarah, and John. Sarah had recently completed a Master of Arts degree in conflict education. Shortly after completing her master's degree, she came to Bangladesh to work as a consultant for an NGO providing educational services in the refugee camps. John had worked with various NGOs in the USA, Pakistan, and Bangladesh for over five years. He had been working with an NGO in Bangladesh shortly after the crisis started in the fall of 2017. While working for this NGO, he was directly involved in planning and implementing educational curricula in the learning centers set up by his employer. The names of the Bengali and Rohingya aid workers were Harris and Yusuf. Harris had been working for various aid organizations and NGOs in Bangladesh for over 10 years. He is currently working as a consultant for an aid organization providing educational services in the camps. Yusuf came to Bangladesh as a refugee shortly before the crisis broke out in Myanmar in 2017. While in Bangladesh, he was able to acquire training with various NGOs and currently works as an educational coordinator for an NGO providing services in the camps. Yusuf manages the resources, training, and support of teachers working in four different learning centers in the refugee camps.

Interviews were semi-formal and semi-structured offering open-ended questions about: (1) the availability of educational programming to Rohingya refugees; (2) educational initiatives in the camps; (3) educational programming for the preservation of religious and cultural identity; (4) and challenges faced by educators and aid workers in the camps. Through this critical ethnographic approach, the data collection aimed to "recogniz[e] the authority of the experiencer to inform the ethnographer's ignorance" (Smith 2005, p. 138). Upon completing the interviews, the audio recordings were transcribed to facilitate data analysis. Data collection of interviews and observations were collected in October 2019.

Questioning for interviews commenced upon establishing a non-threatening and non-evaluative environment in order to encourage participants to "feel free to speak about their issues and concerns openly" (Liamputtong 2011, p. 74). This was accomplished by conducting interviews in a familiar location determined by participants in which they felt comfortable, as well as by mentioning at the outset of the interview process that their views and perceptions were framed by their experiences. As such, there were no right or wrong answers. All individual and follow-up interviews were between 45-60 min long. The types of questions that were asked in the interviews aimed to facilitate "talking with" our participants. The questioning included introductory questions aimed at garnering general knowledge of the perspectives of the participants. It also included transition questions to focus in on issues more narrowly, thereafter, moving on to focus questions relating to the research questions, 
and summarizing questions followed by a concluding question (Liamputtong 2011). Prompting and probing questions were also asked to acquire more in-depth explanations and meanings (Conradson 2013).

The interviews were then transcribed which served as data to be analyzed. As Mishler (1997) observes, "[t]here is an endless number of decisions that must be made about the re-representation of speech as text ... which although apparently mundane, have serious implications for how we might understand the discourse" (p. 261). In other words, the methods employed to transcribe interviews have rhetorical functions. Therefore, in transcribing interviews, a conscious effort needs to be taken to represent the discourse in a manner which reflects the participants' views and beliefs. Transcription was done in rounds with various features of talk recorded in each round. We began by focusing on what was said and then, in subsequent rounds, tried to record gaps in speech and intonation. As there is no "one standard, ideal, and comprehensive mode of transcription" (Mishler 1997, p. 271), we transcribed the interviews to accurately purvey the perceptions and responses of the participants to the best of our abilities. This included using italics to indicate emphasis in participants' intonations, as well as repeatedly listening to audio files of the interviews, and comparing them with transcripts to ensure that the meaning of participants' comments were clearly communicated in the transcripts. Additionally, the researchers made use of field notes relating to each question asked in the interviews. These were used specifically to help facilitate any points of confusion while transcribing the interviews.

In phase two of the study, we employed inductive analysis for coding interview transcripts (Thomas 2006) with the intent of constructing our understanding of participants' experiences relating to educational programming, religious and cultural preservation, and challenges faced by educators in the refugee camps. Interviews were coded after listening to the audio recordings and reading each transcript multiple times. Upon completing our analysis of interview transcripts, we wrote up our findings.

\section{Findings and Discussion}

This study involved interviews of teachers of Rohingya refugee children as well as aid workers that have worked in developing and implementing educational programming in the Kutupalong refugee camp. These interviews revealed that the "trajectories of refugees do not fit neatly into the established policy categories of return, local integration, and resettlement. Instead, they are non-linear and complex permutations of migration, exile, and consistently re-imagined futures" (Dryden-Peterson 2017, p. 21). Through analysis of the interviews in phase two of the study, the following themes emerged: educational challenges and realities of Rohingya students; the preservation of Rohingya identity, culture, and language; and the centrality of religious instruction.

Educational challenges and realities of Rohingya students. The curriculum employed by various NGOs and aid organizations providing educational services in the refugee camps has only recently been developed over the past year and a half. As aid workers and teachers working in the camps described, the migration of the Rohingya to Bangladesh was so massive and rapid that aid organizations' efforts at the outset primarily focused on essential needs and services such as food distribution, shelters, and medical care. Once a functional infrastructure was in place for these services, aid organizations began to focus on providing educational programming to the refugees. This, however, proved to be a difficult task, as educating the Rohingya, similar to other refugee groups, was heavily influenced by politics and power structures (Dryden-Peterson 2017). This became increasingly apparent based on the lexicon of participants discussing educational realities for the Rohingya refugees. The schools attended by Rohingya children were officially called and regularly referred to by participants as "temporary learning centers" or TLCs. Aid organizations providing educational services are required to call their schools' TLCs because the Bangladeshi government wants to emphasize that the crisis is temporary and the Rohingya are expected to eventually return back to Myanmar.

The terminology describing educators is also very specific and politically driven. Educators from the host community of Bangladesh are referred to as 'teachers', whereas Rohingya educators teaching in the camps are called 'volunteers'. According to participants, these designations are meant to 
reiterate that the Rohingya are not staying in Bangladesh on a long-term basis. To this end, the Bengali language is not taught to Rohingya students. Rather, students are taught in Burmese and English, which are not their native languages. Ali observed that this caused a number of comprehension issues for his students. To work around this difficulty, Ali and other teachers often supplement their teaching with Rohingya to clarify instruction for students. However, as many of the teachers are Bengali and do not speak Rohingya, this creates a number of communication barriers for students. According to John, if the Rohingya students learned Bengali in the TLCs, it could potentially lead to "the Rohingya integrating into Bangladeshi society". Furthermore, neither the Myanmar nor the Bangladeshi educational curricula were employed in the refugee camps. Rather, it was an independent educational curriculum developed by the Cox's Bazar Education Sector in conjunction with NGOs and aid organizations. Harris explains that "Myanmar opposed their curriculum to be used and Bangladesh also refused, neither country wants these people to be there, so they had to develop another curriculum". According to a study by Olney et al. (2019), the refugee population feels the Myanmar educational curriculum is essential for them and their children to learn. Participants of this study noted that if students learn the curriculum developed for them in the camps, which is neither Burmese or Bengali "there will not be progress or change to our situation ... The Burmese curriculum is useful for students because we learned it ourselves. And one day we have to return to our country" (p. 38).

The curriculum employed in the camps is still in the developmental phase and only covers years one to four. The subjects taught in the years one to four curriculum include: English, Burmese, Math, Science, and Life Skills. As children living in the camps have had limited access to education in Myanmar and have had their education disrupted through the migration process, schooling of years one to four entails children four to twelve-years-old (Cox's Bazar Education Sector 2018). Children classified as 'adolescents' and 'youth', ages thirteen to eighteen and nineteen to twenty-four, respectively, do not have access to formal educational curricula (Cox's Bazar Education Sector 2018). Rather, some NGOs have set up adolescent learning centers and home-based learning centers for this segment of the Rohingya population (Olney et al. 2019). These learning centers do not follow a set curriculum. Rather, they focus on teaching various types of skills, such as sewing and cleaning, which can assist in finding a means for income or employment in the refugee camps. However, as Harris describes, the education available to the Rohingya does not prepare students for a life beyond the refugee camps:

Interviewer: Do you believe that through this education [in TLCs and youth learning centers] that children receive in these camps, that there's some opportunity for social mobility?

Harris: Very difficult to say. The education that we're providing to this Rohingya children, it will definitely make some attitudinal and behavioral change in the children. They are learning life skills, health messages, something like that. But definitely I don't think it will allow them to get jobs after going back to Myanmar because there is no certificate and the curriculum is not recognized by Myanmar.

Harris was slightly more optimistic about the youth learning centers. Despite not following a formalized curriculum, Harris described how these centers operate systematically, allotting a specific number of classes and hours for various trades. However, the learning centers are very limited in their capacity and not easily accessible in the camps due to limited physical and human resources.

Ultimately, the education available to Rohingya students is meant to provide skills that can possibly lead to some type of basic work in the camps or with an NGO within the camps. The education does not provide them with any type of skills for work outside the camps, because the Rohingya essentially cannot leave the camps. There are major gaps in educational services for adolescents and youth. These gaps are even more pronounced for girls and young women, as Sarah observes:

Sarah: As of last week for example, camp 1 shut down all of their home-based learning centers [for adolescents and youth], which is unfortunate because home-based learning centers were often a solution for agencies to increase access for girls ... I think due to security concerns, 
camp 1 started to close these down, all of their home-based learning centers. And it directly impacts the beneficiaries. Girls' education in particular. The participation rate is pretty low ... [girls' attendance] above the age of 12 tends to drop dramatically. It's the idea that once girls hit puberty, they need to stay home.

Participants described how many girls stop going to schools after the age of puberty in the non-gender segregated learning centers. This drop in female student participation in schooling can be partially explained by conservative social norms, strict religious interpretations, as well as safety concerns for young women and girls in the camps (Cox's Bazar Education Sector 2018). However, the experience of the Rohingya is not unique in this respect, as educational gaps and barriers to access education for girls and young women often occurs in post-conflict settings (Sharkey 2008). Aid organizations have attempted to set up home-based learning centers to help increase access to education for ages thirteen to twenty-four, especially for girls, but in some parts of the camp, according to Sarah, they have been shut down due to security concerns and fears over human trafficking.

Beyond the difficulties associated with lack of access to education of various segments of the Rohingya population and the limited formal curriculum that is currently being offered to Rohingya students in years one to four, participants voiced serious concern over the quality of teachers and teacher training in the camps. For example, in the course of interviewing teachers who taught English in the TLCs, interviewers were required to communicate with the teachers through a translator, as they were unable to understand the questions or convey their experiences in English. Educators in the camps are required to have completed year ten of their education in Myanmar or Bangladesh, which is equivalent to a secondary level of education. However, due to a major lack of qualified teachers, this is not always the case, as Hussain observes:

Interviewer: Do you feel that through the education in the camps there's more opportunities for Rohingya to do work in the camps or beyond the camps?

Hussain: They will, if they can complete level four, they can get job within the camp, but not outside the camp.

Interviewer: What kind of jobs can they get?

Hussain: They may get like, the cleaner, washman, they can be teacher.

Interviewer: Don't you have to be class 10 pass to become a teacher?

Hussain: Yeah, but though the standard is like that, some organizations are recruiting, like class 4 or 5 , because there's a lack of educated person in the camp ... when we went to the clinic, we saw our student who was teaching. She's not class 10 pass, she's only level 4.

According to Hussain, the basic level of education that is offered to Rohingya students in the camps, due to severe shortages of qualified teachers, can be sufficient to potentially become a teacher in the camps. As such, under the current circumstances, there is an extremely low threshold for teacher training and qualifications (Olney et al. 2019). These educational deficits are further aggravated due to a severe lack of teaching materials available in the learning centers and massive student teacher ratios of over 50 students per teacher (Cox's Bazar Education Sector 2018). There have been efforts by aid organizations to train teachers more effectively. However, logistically providing training for teachers has proven to be difficult to manage and coordinate:

Interviewer: Do you believe there are any opportunities for capacity building for teachers in the camps, in terms of training them better?

John: The [education] sector will help with providing curriculum and some kind of guideline for teacher trainings but consistency is a big issue. Logistically, being able to do that in the 
camps is also another big issue. There's a lot of coordination effort that has to go in to pulling that kind of stuff off. There's no space ... standardization of teacher training is definitely something that's needed but it's a bit of a logistical nightmare ... let me give you an example, you may have 30 TLCs in one camp, so where are you going to bring 30 teachers to one space? So that's an issue. Then you have 30 Rohingya teachers and 30 host community teachers. Host community teachers can technically teach outside the camp, Rohingya teachers can't, so then you have to figure out a strategy to teach the host community teachers somewhere else and the Rohingya somewhere else, and that causes discrepancies amongst them to be unified.

The educational deficits caused by the lack of teacher training, professional development, and teaching materials is compounded by the fact that assessments to ensure learning outcomes are attained are completely absent from the schooling provided to Rohingya students. Students are not assessed in a summative manner to distinguish if they have attained the learning outcomes of the curriculum in years one to four. Consequently, there are no certificates issued attesting to the students abilities or their attainment of learning objectives to warrant promotion to subsequent educational levels. They simply move from one educational level to the next upon completing modules of content for a given subject, which can create major educational roadblocks for the students beyond the context of the refugee camps. As Sarah observes:

Sarah: There's no accreditation. The fact that kids can move on from year two to year three has no value if they next year go back to Myanmar. Where's the evidence of that? So, it's hard to say if the education they're receiving here will be able to give them any sort of viable upward mobility if there's no sort of explicit certificate for it.

Another major impediment for Rohingya students to succeed in their schooling is the lack of psychological and social support available to children in the TLCs. A number of the children in the camps have witnessed horrific things and are survivors of trauma. All the teachers interviewed in this study described how a number of their students suffer from emotional distress and exhibit behaviors such as being distracted, withdrawn, unable to communicate with others, social isolation, and are unable to make relationships with their peers due to their experiences associated with the forced migration to Bangladesh. However, the teachers, by their own admission, have limited resources and training to be able to address these challenges in their classes. As John noted, "they aren't even trained to be teachers, how are they going to be trained psychologists?" Beyond the curriculum and instruction available to Rohingya students in the TLCs, there are some informal outlets for Rohingya students to learn about aspects of their cultural identity. The paper turns now to discuss how Rohingya identity, culture, and religious traditions have been preserved through educational outlets in the refugee camps.

Preservation of identity, culture, and language. Participants expressed very serious concerns over Rohingya students losing elements of their cultural identity in Kutupalong. The majority of participants felt that language was an aspect of their culture that could be diminished or lost over time, as the education available to Rohingya students is exclusively in Burmese and English. Furthermore, the existing year one to four curriculum did not focus at all on Rohingya history or the preservation of Rohingya culture. When describing the gravity of the issue, Ali observed, "if the [the Rohingya] will stay here long time, then they will lose their identity as well as their culture, as most of the Rohingya are uneducated persons ... there's no opportunity to practice our culture and language". In light of these realities, some teachers, as mentioned by Hussain, have made attempts to bring up topics of history or culture in their classes, however, this is not a part of the official curriculum. This sentiment was expressed by John:

Interviewer: Do you think Rohingya children are at risk of losing their sense of identity and culture growing up in the camps?

John: One hundred percent! 
Interviewer: How so, and why?

John: Until now, you don't really have any kind of catered materials employed for any kind of cultural reinforcement of the Rohingya population. First of all, you deny their language even exists as a written script, you're not willing to teach it. That doesn't help.

Language preservation was a major issue that came up in aid worker and educator interviews, when discussing concerns of the Rohingya losing aspects of their cultural identity. As alluded to by John, some are of the opinion that Rohingya does not exist as a written language. However, based upon our conversations with aid workers and educators, efforts have been made to codify Rohingya as a written language. Furthermore, when asked if instruction for cultural reinforcement and language was absent because of a lack of materials, John informed us that materials have existed since the onset of the crisis. John felt that these materials could be further developed; however, due to the political nature of education in Kutupalong, these materials were never used nor were there any attempts to develop them. The Rohingya do not have formal access through education to their native language; the educational curriculum that has been developed for them does not provide any kind of cultural reinforcement about their history and customs, and prior to the crisis, the Rohingya have been a stateless people. All of these factors combined have created circumstances, which our participants felt will lead to a diminishing of Rohingya identity and culture, while living in the refugee camps. One area of education that has been essential for the preservation of aspects of Rohingya identity has been through religious education.

The centrality of religious instruction. The Rohingya had very limited access to education prior to the current crisis (Ibrahim 2018). As such, religious instruction had a very prominent role in Rohingya society, as it was one educational outlet that was available to them without major impediments. As John notes, "religious education is massive because in Rakhine, everyone was restricted, had limited access to education, so madrassas were your place". Consequently, religious instruction has remained a fundamental aspect of Rohingya life in the refugee camps. According to a United Nations Refugee Agency (UNHCR) analysis, Rohingya children in the refugee camps engaged with madrassa-based learning more than any other type of learning environment available in the camps, with 60-80 percent of adolescents and youth attending, compared to 60 percent attendance or lower in learning centers (Cox's Bazar Education Sector 2018). The madrassas are perceived as safe spaces by both parents and children, which fosters a sense of communal life in the refugee camps (Olney et al. 2019).

All participants that we interviewed unanimously agreed that parents of children growing up in the refugee camps felt that religious identity and instruction were important and strongly encouraged among the Rohingya population. Sakina and Salma described how the Rohingya had a very strong sense of religious pride, and parents of children felt it was important for them to learn basic religious principles and teachings. Despite the importance attached to religious values and instruction amongst the refugee population, religious instruction was not formally taught through the schooling that children received in the camps. As such, the only access parents had for religious instruction for their children was through informal Islamic teaching spaces referred to as maktabs and madrassas in the camps (the main difference being that the focus in the former is on learning to recite the Quran whereas the latter includes Quran memorization; basic religious education may be offered at both).

Religious instruction is relatively well-attended by Rohingya students at various age levels, and given the importance attached to this type of education, a significant network of maktabs and madrassas has emerged in the refugee camps. Girls and young women are far more likely to engage with these types of learning environments than non-religious learning centers. This highlights the need to engage with moderate religious leadership, which could potentially help promote secular education for girls and young women in these spaces (Olney et al. 2019). According to Olney et al. (2019), some of the religious leadership of these maktabs and madrassas were open to combining religious and secular learning within their networks. This could potentially help create more avenues for access to education for Rohingya youth between the ages of thirteen to twenty-four, given the severe shortage 
of learning centers available to this demographic. This approach to educational programming in the camps would particularly be beneficial for girls and young women, as these learning environments are strictly segregated and would therefore be in line with the cultural norms of the Rohingya community. However, a number of challenges remain; the most pressing of which are the lack of qualified educators available to work in the refugee camps, and underdeveloped educational curricula (Cox's Bazar Education Sector 2018).

The maktabs and madrassas did not have a defined curriculum. According to participants, these religious learning spaces primarily consisted of classes for learning how to read and memorize Quran, as well as some other religious materials containing hadith literature. In the absence of a formal curriculum, there were no standardized texts being used or any kind of uniform literature available. When asked about the teachers in these spaces, it was unclear to participants what qualifications the teachers needed to hold these positions. Most participants stated that they were people that were either recognized by their peers within their communities as qualified religious instruction educators or they were imams in Myanmar before the exodus. When participants were asked whether they had fears or concerns about children being miseducated or learning inappropriate ideas about Islam, such as radicalized views and extremist ideologies, the vast majority of participants felt that this was not a major concern. Participants felt this way because traditionally, the education received in maktabs and madrassas in Myanmar almost exclusively focused on Quran recitation and memorization and very little else. This was also the case in the maktabs and madrassas in the camps. Furthermore, most of the maktabs and madrassas have received permission by camp authorities to function in the camps openly (Olney et al. 2019).

Despite the lack of concern of participants over these issues, in the absence of a standards-based religious curriculum, there are probabilities for misinformation and erroneous views to emerge through these informal learning centers. This situation can only be exacerbated when people are living in a situation where they have been oppressed, wronged, and denied basic human rights and dignity. When asked by participants why they felt there was no religious instruction formally provided by the government or aid agencies in the camps, participants felt that the primary concern of people administering the aid efforts in the camps was the basic needs and survival of the refugee population. As such, the limited resources that were available in the camps were focused towards provision of food, shelter, healthcare, and the basic year one to four education provided by the TLCs in the camps. However, as the refugees continue to linger in the camps indefinitely, and with little to no hope of any resolution of this conflict in the near future, religious education continues to be an area of pressing concern, as it is a primary source of education for Rohingya youth, yet it is severely underdeveloped.

\section{Conclusions}

This article examined the educational realities of Rohingya refugees in the Kutupalong refugee camp near Cox's Bazar in southeast Bangladesh. With limited resources and international support, a number of educational challenges exist for the student-aged Rohingya refugees, who represent over half the Rohingya population (Cox's Bazar Education Sector 2018). Through a critical ethnographic approach, participants were able to voice their concerns and experiences with educational programming available to Rohingya students to help construct the researchers' understandings of educational challenges and realities in the camps.

Participants expressed that there were a number of deficits and barriers facing Rohingya students such as underqualified teachers, the lack of standardized qualifications for educators, inaccessibility to learning centers for Rohingya students ages thirteen to twenty-four, the lack of teaching materials, as well as cultural barriers for girls and young women seeking an education. Islamic education was viewed by participants as a fundamental source of education for Rohingya youth. Though Islamic education in the Rohingya refugee camps was not formalized or organized through a curriculum or standards, it was valued as an essential aspect of Rohingya education and identity. The maktabs and madrassas were perceived as safe spaces for Rohingya students, particularly for young girls and 
women, as the classes were gender segregated. This reality highlights the importance of progressive religious leadership in the Rohingya refugee camps, as tremendous potential exists to make general education more accessible to Rohingya adolescents and youths aged thirteen to twenty-four within these religious educational spaces. Though some religious leadership had expressed an openness to providing secular schooling alongside religious instruction in the maktabs and madrassas (Olney et al. 2019), without substantial support from NGOs, relief organizations, and the international community, the primary issues of underqualified teachers, lack of educators and teaching resources, and underdeveloped educational curricula remain.

Additionally, this study highlights a number of paradoxes in the educational experiences of Rohingya students in the Kutupalong refugee camps. For example, Rohingya refugee students' languages of instruction are English and Burmese. For the Rohingya, the Burmese language is associated with oppression and hegemony, yet it has been given precedence over their native dialect. Many Rohingya have prioritized Islamic religious instruction for their children in the refugee camps. This may seem unusual as the Rohingya have been oppressed for generations partly for their religious identity. This study also provides important insights about refugee education curriculum development, teacher training and development in post-conflict educational settings, and the importance of religious instruction for refugee students.

Further studies to develop this research could focus on the potential for developing formalized Islamic educational curricula in the maktabs and madrassas that could function alongside the evolving secular curriculum in the refugee camps as a means of helping to preserve and promote Rohingya identity and culture. Additionally, such a study could examine the potential for creating opportunities for girls and young women to gain increased access to education in the camps through Islamic educational spaces. A total of eight participants were interviewed for this study. Given that this study was a critical ethnography, we were less concerned with the sample size and more focused on engaging in a critical dialogue with our participants (Quantz 1992). By interviewing a smaller number of participants, this inquiry was able to provide rich contextualized data unattainable in a larger scale inquiry. Having a smaller number of participants allowed for detailed and reflective responses to questions and inquiries, as well as the possibility for engaging in detailed follow-up questions and interviews.

Author Contributions: N.B. was the primary researcher and writer, S.W. was involved in writing, editing, and facilitated the ground work for the field study through OBAT Canada. Both authors have read and agreed to the published version of the manuscript.

Funding: This research was funded by the American University in Dubai. Logistical support was provided by OBAT Canada.

Conflicts of Interest: The authors declare no conflict of interest.

\section{References}

Bari, Muhammad Abdul. 2018. The Rohingya Crisis: A People Facing Extinction. Leicestershire: Kube Publishing.

BBC. 2020. BBC News, World. Available online: https://www.bbc.com/news/world-asia-51221029 (accessed on 23 January 2020).

Budd, John M. 2008. Critical theory. In The Sage Encyclopedia of Qualitative Research Methods. Edited by Lisa M. Given. Thousand Oaks: Sage Publications, pp. 17174-179.

Carspecken, Phil Francis, and Francis Carspecken. 1996. Critical Ethnography in Educational Research. New York: Routledge.

Conradson, David. 2013. Focus groups. In Methods in Human Geography: A Guide for Students Doing a Research Project, 2nd ed. Edited by Robin Flowerdew and David Martin. New York: Routledge, pp. 128-43.

Cook, Kay. 2008. Critical ethnography. In The Sage Encyclopedia of Qualitative Research Methods. Edited by Lisa M. Given. Thousand Oaks: Sage Publications, pp. 148-51.

Cox's Bazar Education Sector. 2018. Joint Education Needs Assessment: Rohingya Refugee in Cox's Bazar June 2018. Cox's Bazaar: Cox's Bazar Education Sector. 
Dryden-Peterson, Sarah. 2016. Refugee Education: The Crossroads of Globalization. Educational Researcher 45: 473-82. [CrossRef]

Dryden-Peterson, Sarah. 2017. Refugee education: Education for an unknowable future. Curriculum Inquiry 47: 14-24. [CrossRef]

Habib, Mohshin, Christine Jubb, Salahuddin Ahmad, Masudur Rahman, and Henri Pallard. 2018. Forced Migration of Rohingya: The Untold Experience. Ottawa: Ontario International Development Agency, Canada.

Harris, Kathleen. 2018. CBC: Politics. Available online: https://www.cbc.ca/news/politics/rohingya-camp-canadamotion-1.4836078 (accessed on 25 September 2018).

Ibrahim, Azeem. 2018. The Rohingyas: Inside Myanmar's Genocide. London: Hurst Publishers.

Liamputtong, Pranee. 2011. Focus Group Methodology. Thousand Oaks: Sage.

McPherson, Poppy. 2017. Times: World. Available online: https://time.com/4922715/myanmar-rohingya-violencerakhine/ (accessed on 31 August 2017).

Médecins Sans Frontières. 2018. 'No One Was Left Behind': Death and Violence against the Rohingya in Rakhine State, Myanmar. Geneva: Medecins sans Frontieres.

Mishler, Elliot G. 1997. Representing discourse: The rhetoric of transcription. Journal of Narrative and Life History 1: 255-80. [CrossRef]

OCHA. 2020. UNOCHA, Rohingya Refugee Crisis. Available online: https://www.unocha.org/rohingya-refugeecrisis (accessed on 15 January 2020).

Olney, Jessica, Haque Nurul, and Mubarak Roshid. 2019. We Must Prevent a Lost Generation: Community-Led Education in Rohingya Refugee Camps. Oslo: Peace Research Institute Oslo.

Quantz, Richard A. 1992. On critical ethnography (with some postmodernist considerations). In The Handbook of Qualitative Research in Education. Edited by Margaret LeCompte, Wendy Millroy and Judith Preissle. San Diego: Academic Press, pp. 447-505.

Seekins, Donald M. 2008. The social, political and humanitarian impact of Burma's cyclone Nargis. Asia-Pacific Journal 6: 1-13.

Sharkey, Donna. 2008. Contradiction is girls' education in a post-conflict setting. Compare 38: 569-79. [CrossRef]

Simmons, Marlise. 2019. New York Times: World. Available online: www.nytimes.com/2019/11/11/world/asia/ myanmar-rohingya-genocide.html (accessed on 11 November 2019).

Smith, Dorothy E. 2005. Institutional Ethnography: A Sociology for People. Lanham: AltaMira Press.

The United Nations High Commissioner for Refugees. 2019. UNHCR: Situations. Available online: https: //data2.unhcr.org/en/situations/myanmar_refugees (accessed on 30 September 2019).

The United Nations. 2018. United Nations: News. Available online: news.un.org/en/focus/rohingya-refugee-crisis (accessed on 2 July 2018).

Thomas, David R. 2006. A general inductive approach for analyzing qualitative evaluation data. American Journal of Evaluation 27: 237-46. [CrossRef]

Topol, Sarah A. 2019. The school teacher and the genocide. The New York Times Magazine, August 11, $29-37$.

United Nations News. 2018. United Nations: News. Available online: news.un.org/en/story/2018/03/1004232 (accessed on 6 March 2018).

Wade, Francis. 2017. Myanmar's Enemy Within. London: Zed Books.

Ware, Anthony, and Costas Laoutides. 2018. Myanmar's 'Rohingya' Conflict. New York: Oxford University Press.

(C) 2020 by the authors. Licensee MDPI, Basel, Switzerland. This article is an open access article distributed under the terms and conditions of the Creative Commons Attribution (CC BY) license (http://creativecommons.org/licenses/by/4.0/). 